\title{
An Adenine-Thiamin Auxotrophic Mutant of Bacillus subtilis
}

\author{
By STANLEY A. ZAHLER \\ Division of Biological Sciences, Cornell University, \\ Ithaca, New York 14853, U.S.A.
}

(Received 22 February 1978)

\section{INTRODUCTION}

In Salmonella typhimurium and Escherichia coli, the five biosynthetic steps that lead from 5-phospho- $\alpha$-D-ribose 1-pyrophosphate to 5'-phosphoribosyl-5-aminoimidazole are common to the pathways that lead to purine nucleotide synthesis and to the synthesis of the pyrimidine moiety of thiamin. Mutations that prevent the synthesis of 5'phosphoribosyl-5aminoimidazole cause auxotrophy for both adenine and thiamin. Such mutations were first described iby Yura (1956), and the explanation for their dual requirement was given by Newell \& Tucker (1968). The identification of the genes for the five enzymes can be found in the bibliographies of the most recent editions of the genetic maps for $S$. typhimurium (Sanderson, 1972) and E. coli (Bachmann, Low \& Taylor, 1976).

In 1974, as part of a classroom exercise, Mr Thomas Patterson isolated an adeninethiamin (Ath-) auxotroph of Bacillus subtilis in my laboratory. After preliminary characterization we named the mutation ath-1. A strain carrying the mutation was given the accession number CU869 and placed in our stock collection.

Recently, Walter \& Bacher (1977) described mutants defective in thiamin biosynthesis in B. subtilis. Although these authors isolated 224 adenine auxotrophs and 53 thiamin auxotrophs, they were unable to find any $A^{-} t^{-}$mutants. Their failure to isolate Ath $^{-}$mutants might imply that $B$. subtilis has either a novel biosynthetic pathway, or duplicate pathways for the synthesis of purines and thiamin. The Ath- strain cu869 belies this conclusion. A brief description of strain CU869 seems appropriate.

\section{METHODS}

Bacteria. Bacterial strains were all derived from Bacillus subtilis strain 168, and are listed in Table 1. The $\operatorname{trp} C 2$, hisA1, purB6, leuA169 and ath-1 mutations caused auxotrophy for tryptophan, histidine, adenine, leucine, and adenine plus thiamin, respectively. The fur $B$ mutations permitted bacteria to grow in the presence of $40 \mu \mathrm{g}$ uracil $\mathrm{ml}^{-1}$ and $40 \mu \mathrm{g}$ 5-fiuorouracil ml-1. The tre-12 mutation prevented growth when $400 \mu \mathrm{g}$ trehalose $\mathrm{ml}^{-1}$ replaced glucose in minimal agar.

Culture media and growth conditions. These have been described previously (Ward \& Zahler, 1973). Minimal agar contained $10 \mu \mathrm{g}$ tryptophan $\mathrm{ml}^{-1}$. When required, $1 \mu \mathrm{g}$ thiamin. $\mathrm{HCl}$ or $20 \mu \mathrm{g}$ adenine ml ${ }^{-1}$ was added.

Materials. The mutagen 6-chloro-9[(3-[(2-chlorethyl)-amino]propyl) amino]-2-methoxyacridine (ICR-191) was a gift from Dr Hugh Creech. Other chemicals were purchased from Sigma.

Mutagenesis. A culture of B. subtilis strain cu614 (trpC2 leuA169) was grown to stationary phase in Antibiotic Medium No. 3 (Difco), and then diluted $10^{-6}$ into the same medium containing $10 \mu \mathrm{g} \mathrm{ICR}-191 \mathrm{ml}^{-1}$. (The presence of the leucine auxotrophy in this strain was not related to the subject of this communication.) The culture was incubated with aeration for $16 \mathrm{~h}$ at $37^{\circ} \mathrm{C}$. Then the cells were washed in buffer $(0 \cdot 1 \mathrm{M}-\mathrm{NaCl}$, $0.05 \mathrm{M}$-sodium citrate) and appropriate dilutions were made. About 5000 bacteria were spread on each of several plates of minimal agar containing $40 \mu \mathrm{g}$ leucine $\mathrm{ml}^{-1}$. The plates were examined after $24 \mathrm{~h}$ incubation. Micro-colonies, being fed by the small colonies on the plate, were picked with the aid of a dissecting microscope and characterized with respect to new growth requirements. Among approximately 300 new auxotrophic mutants identified this way (and another 300 induced by $N$-methyl- $N^{\prime}$-nitro- $N$-nitrosoguanidine and screened in the same way), only one was Ath-.

To test for reversions of cu869 to non-requirement for thiamin alone or for adenine alone, about $10^{8}$ bacteria were spread on minimal agar plates containing either adenine (for thiamin prototrophy) or $0.1 \mathrm{ml}$ 
Table 1. Bacillus subtilis strains

\begin{tabular}{|c|c|c|}
\hline Strain no. & Strain genotype & Source or reference \\
\hline BR19 & $\operatorname{trp} C 2 \operatorname{his} A I$ & J. Spizizen \& B. E. Reilly \\
\hline BR62 & $\operatorname{trp} C 2$ purB6 & J. Spizizen \& B. E. Reilly \\
\hline Cu120 & $\operatorname{trp} C 2$ & $\begin{array}{l}\text { J. Spizizen \& B. E. Reilly (formerly strain } 168 \text {; } \\
\text { Spizizen, 1958) }\end{array}$ \\
\hline Cu614 & $\operatorname{trpC2}$ leuA169 & Ward \& Zahler (1973) \\
\hline Cu637 & $\operatorname{trp} C 2$ furB1 & $\begin{array}{l}\text { Spontaneous fluorouracil-resistant mutant of } \\
\text { cu120; this laboratory }\end{array}$ \\
\hline cu660 & $\operatorname{trp} C 2$ purB6 furB4 & $\begin{array}{l}\text { Spontaneous fluorouracil-resistant mutant of } \\
\text { BR62; this laboratory }\end{array}$ \\
\hline CU869 & trpC2 ath-1 & See text \\
\hline Cu1004 & $\operatorname{trpC2}$ tre-12 furB 4 & $\begin{array}{l}\text { Constructed by PBS1 transduction of } \\
\text { cU } 660 \text { by phage grown in strain QB } 870 \\
\text { from J.-A. Lepesant }\end{array}$ \\
\hline
\end{tabular}

Antibiotic Medium No. 3 per plate and thiamin (for purine prototrophy). Then $5 \mu \mathrm{l}$ of a solution containing $500 \mu \mathrm{g}$ ICR-191 ml-1 was placed on the surface of each spread plate. On incubation, a ring of revertant colonies appeared around the site where the mutagen had been applied.

Transduction and transformation. The genetic methods have been described previously (Ward \& Zahler, 1973). A minor variation of the transformation technique of Anagnostopoulos \& Spizizen (1961) was used. Recipients $\left(1.0 \mathrm{ml}\right.$ ) were grown for $4.5 \mathrm{~h}$ in the first-stage medium, and then diluted $10^{-1}$ (without washing) into $0.45 \mathrm{ml}$ of the second-stage medium lacking tryptophan. Selection for $\mathrm{Ath}^{+}$was made on minimal agar containing, in some cases, $20 \mu \mathrm{g}$ adenine $\mathrm{ml}^{-1}$.

Production of strain cu869. DNA was extracted from the original ICR-191-induced auxotroph and used at high concentration to transform strain $\mathrm{BR} 19$ to $\mathrm{His}^{+}$. Since excess DNA was used, some of the transformants were simultaneously transformed to $\mathrm{His}^{+}$and to $\mathrm{Ath}^{-}$, although his $\mathrm{Al}$ and ath-l are not linked genetically. One such congressant, strain cu869, was purified and used in the experiments described below.

\section{RESULTS AND DISCUSSION}

\section{Is ath-1 a single mutation?}

The ath-1 mutation present in strain cu 869 was originally induced by ICR-191, a frameshift mutagen. As is usually the case with such mutations, reversions were also induced by ICR-191. In addition, rare spontaneous revertants were found at approximately one per $10^{9}$ cells plated. Of two spontaneous and 20 mutagen-induced mutations permitting growth without thiamin, all permitted growth without adenine as well. Of two spontaneous and 12 mutagen-induced mutations permitting growth without adenine, all permitted growth without thiamin as well. It is concluded that ath-1 is a single mutation rather than two closely linked mutations.

\section{Genetic mapping of the ath-1 mutation}

Preliminary tests showed that the transduction of strain cU869 with phage PBS1 grown in strain cu1004 resulted in cotransduction of tre-12 with $a t h^{+}$in 20 of $44 \mathrm{Ath}^{+}$transductants. A PBS1-mediated transduction of strain cu869 by phage grown in strain cu637 gave cotransduction of $f u r B I$ with $a t h^{+}$in 8 of $70 \mathrm{Ath}^{+}$transductants. The tre-12 marker is $29 \%$ cotransduced with purB6 (Lepesant-Kejzlarovà et al., 1975). The furB1 marker is $10 \%$ cotransduced with purB6 (unpublished results). These data suggested that ath-1 is located near purB on the B. subtilis chromosome (Young \& Wilson, 1975).

Strain CU869 was transduced to $a t h^{+}$by phage PBS1 grown in strain cu660, which carries the purB6 marker. Selection for $\mathrm{Ath}^{+}$was made on minimal agar containing adenine. Of $115 \mathrm{Ath}^{+}$transductants tested, 112 were $\mathrm{Ade}^{-}$and carried the purB6 allele. Thus purB6 was $97 \%$ cotransduced with $a t h^{+}$.

To test for linkage between ath-1 and purB6 by transformation, cU869 was transformed with DNA extracted from strain BR62, which carries purB6, and with DNA from the 
prototrophic strain cu120. The selective agar contained adenine. Of $122 \mathrm{Ath}^{+}$transformants tested from the transformations using BR62 as donor, 103 were Pur- $^{-}(84 \%$ cotransformation of purB6 with $a t h^{+}$). Of $94 \mathrm{Ath}^{+}$transformants tested from the transformations using cu120 as donor, all were $\mathrm{Pur}^{+}$, as expected; the adenine and thiamin requirements were always transferred together.

It is concluded that ath- 1 is a single mutation, tightly linked to pur B6. No nearby markers are available for determining the orientation of ath-1 and purB 6 on the chromosome.

I thank Dr Hugh Creech for a gift of ICR-191. This research was supported in part by Grant 76-82221 from the National Science Foundation.

\section{REFERENCES}

Anagnostopoulos, C. \& Spizizen, J. (1961). Requirements for transformation in Bacillus subtilis. Journal of Bacteriology 81, 741-746.

BachmanN, B. J., Low, K. B. \& TAYlor, A. L. (1976). Recalibrated linkage map of Escherichia coli $\mathrm{K}-12$. Bacteriological Reviews 40, 116-167.

LePeSANT-KeJZlarovà, J., LePeSANT, J.-A., WALle, J., Billault, A. \& Dedonder, R. (1975). Revision of the linkage map of Bacillus subtilis 168: indications for circularity of the chromosome. Journal of Bacteriology 121, 823-834.

Newell, P. C. \& TuCKer, R. G. (1968). Biosynthesis of the pyrimidine moiety of thiamine. A new route of pyrimidine biosynthesis involving purine intermediates. Biochemical Journal 106, 279-287.

SANDERSON, K. E. (1972). Linkage map of Salmonella typhimurium, edition IV. Bacteriological Reviews 36, 558-586.

SPIZIzEN, J. (1958). Transformation of biochemically deficient strains of Bacillus subtilis by deoxyribo- nucleate. Proceedings of the National Academy of Sciences of the United States of America 44, 1072-1078.

WALTER, W. \& BACHER, A. (1977). Biosynthesis of thiamin in Bacillus subtilis. Isolation of mutants accumulating 4-amino-5-hydroxymethyl-2-methylpyrimidine phosphate. Journal of General Microbiology 103, 359-366.

WARD, J. B. \& ZAHLER, S. A. (1973). Genetic studies of leucine biosynthesis in Bacillus subtilis. Journal of Bacteriology 116, 719-726.

Young, F. E. \& Wilson, G. A. (1975). Chromosomal map of Bacillus subtilis. In Spores VI, pp. 596614. Edited by P. Gerhardt, R. N. Costilow \& H. L. Sadoff. Washington: American Society for Microbiology.

YuRA, T. (1956). Evidence of non-identical alleles in purine-requiring mutants of Salmonella typhimurium. Carnegie Institution of Washington Publication 613, 63-75. 